\title{
Nonpharmacological management of procedural pain in infants and young children: An abridged Cochrane review
}

\author{
Rebecca Pillai Riddell PhD ${ }^{1,2}$, Nicole Racine $M A^{1}$, Kara Turcotte $\mathrm{BA}^{1}$, Lindsay S Uman PhD ${ }^{3}$, Rachel Horton $\mathrm{MA}^{1}$, \\ Laila Din Osmun MA ${ }^{1}$, Sara Ahola Kohut MA ${ }^{1}$, Jessica Hillgrove Stuart MA ${ }^{1}$, Bonnie Stevens RN PhD FCAHS ${ }^{4}$ Diana Lisi BA ${ }^{1}$
}

\begin{abstract}
R Pillai Riddell, N Racine, K Turcotte, et al. Nonpharmacological management of procedural pain in infants and young children: An abridged Cochrane review. Pain Res Manage 2011;16(5):321-330.
\end{abstract}

BACKGROUND: Acute pain and distress during medical procedures are commonplace for young children.

OBJECTIVE: To assess the efficacy of nonpharmacological interventions for acute procedural pain in children up to three years of age.

METHODS: Study inclusion criteria were: participants $<3$ years of age, involved in a randomized controlled or crossover trial, and use of a 'notreatment' control group (51 studies; $\mathrm{n}=3396$ ). Additional studies meeting all criteria except for study design (eg, use of active control group) were qualitatively described $(\mathrm{n}=20)$.

RESULTS: For every intervention, data were analyzed separately according to age group (preterm-born, term-born neonate and older infant/young child) and type of pain response (pain reactivity, immediate pain-related regulation). The largest standardized mean differences (SMD) for pain reactivity were as follows: sucking-related interventions (preterm: -0.42 [95\% CI -0.68 to -0.15$]$; neonate -1.45 [CI -2.34 to -0.57$]$ ), kangaroo care (preterm -1.12 [95\% CI -2.04 to -0.21$]$ ), and swaddling/facilitated tucking (preterm -0.97 [95\% CI -1.63 to -0.31$]$ ). For immediate painrelated regulation, the largest SMDs were: sucking-related interventions (preterm -0.38 [95\% CI -0.59 to -0.17 ]; neonate -0.90 [CI -1.54 to $-0.25]$ ), kangaroo care 0.77 ( $95 \% \mathrm{CI}-1.50$ to -0.03$]$ ), swaddling/facilitated tucking (preterm -0.75 [95\% CI -1.14 to -0.36$]$ ), and rocking/holding (neonate -0.75 [95\% CI -1.20 to -0.30$]$ ). The presence of significant heterogeneity limited confidence in nonsignificant findings for certain other analyses.

CONCLUSIONS: Although a number of nonpharmacological treatments have sufficient evidence supporting their efficacy with preterm infants and healthy neonates, no treatments had sufficient evidence to support efficacy with healthy older infants/young children.

Key Words: Acute pain; Caregiver; Infant; Pain management

Titial misinterpretations of common infant pain outcomes, such as the lack of declarative memory for painful experiences during infancy (1), the muted responses of premature infants after a barrage of painful procedures (2), and unacceptable rates of serious adverse events due to poor knowledge of infant responses to analgesics and anesthetics during the 1950 s to 1970 s (3), perpetuated widespread neglect of infant pain treatment.

Established research supports infants' anatomical and functional capacity to perceive pain $(4,5)$ and respond to tissue insult in a manner interpretable as pain (6). However, despite significant advocacy work, infant acute pain is still undermanaged or unmanaged (7). Comprehensive meta-analytic reviews of nonpharmacological pain management strategies are essential to the ethical and humane treatment of infants and young children during acutely painful procedures.

While several reviews summarize certain acute pain management techniques for painful procedures in infants and young children

\section{La prise en charge non pharmacologique des douleurs causées par des interventions auprès des nourrissons et des jeunes enfants : une analyse Cochrane abrégée}

HISTORIQUE : Il est courant que les jeunes enfants ressentent une douleur aiguë et de la détresse pendant des interventions médicales.

OBJECTIF : Évaluer l'efficacité de mesures non pharmacologiques pour soulager une douleur aiguë causée par une intervention chez des enfants de moins de trois ans.

MÉTHODOLOGIE : Les critères d'inclusion dans l'étude s'établissaient comme suit : participants de moins de trois ans faisant partie d'un essai aléatoire et contrôlé ou transversal et utilisation d'un groupe témoin « sans traitement » (51 études; $\mathrm{n}=3$ 396). Des études supplémentaires respectant tous les critères sauf la méthodologie (p. ex., recours à un groupe témoin actif) ont fait l'objet d'une description qualitative $(n=20)$.

RÉSULTATS :À chaque intervention, les chercheurs ont analysé les données séparément compte tenu du groupe d'âge (nouveau-né prématuré ou à terme et nourrisson plus âgé ou jeune enfant) et du type de réponse à la douleur (réac tivité à la douleur, régulation immédiate liée à la douleur). Les plus grandes différences movennes standardisées (DMS) de réactivité à la douleur s'établissaient comme suit : interventions liées à la succion (prématuré : $-0,42$ [95 \% IC -0,68 à $-0,15]$; nouveau-né : $-1,45$ [IC $-2,34$ à $-0,57]$ ), technique kangourou (prématuré : $-1,12$ [95\% IC $-2,04$ à $-0,21]$ ) et emmaillotement ou enroulement facilité (prématuré : $-0,97$ [95\% IC -1,63 à -0,31]). En cas de régulation immédiate liée à la douleur, les plus grandes DMS s'établissaient comme suit : interventions liées à la succion (prématuré : $-0,38$ [95\% IC -0,59 à -0,17]; nouveau-né : $-0,90$ [IC $-1,54$ à $-0,25]$ ), technique kangourou : 0,77 (95\% IC $-1,50$ à $-0,03]$ ), emmaillotement ou enroulement facilité (prématuré : $-0,75$ [95\% IC $-1,14$ à $-0,36])$, et fait de bercer ou de prendre dans les bras (nouveau-né : $-0,75$ [95\% $\mathrm{IC}-1,20$ à $-0,30]$ ). Une hétérogénéité importante limitait l'intervalle de confiance des résultats non significatifs de certaines autres analyses.

CONCLUSIONS : Même si les données sont suffisantes pour appuyer l'efficacité d'un certain nombre de traitements chez les prématurés et les nouveau-nés en santé, aucun traitement ne s'associe à des données probantes suffisantes pour en étayer l'efficacité chez les nourrissons plus âgés et les jeunes enfants.

(8-10), no comprehensive meta-analyses were attempted. Moreover, to our knowledge, there have been no meta-analyses conducted on the broad range of nonpharmacological interventions for managing acute pain and distress in young children from zero to three years of age. Given the frequency of acutely painful procedures for healthy children in early childhood (eg, immunizations) and for hospitalized infants (11), this significant gap in the literature deserves a higher priority.

The full review (12) also takes a novel and in-depth look at the nonpharmacological pain management literature by controlling for age and type of pain response. Age was considered crucial due to the steep trajectory of infant development, both psychologically and physiologically. Moreover, given the different physiological and psychological mechanisms subsuming the initial reaction to a painful stimulus (more automatic and/or reflexive reactivity such as initial distress cry) and during the period of recovery from the painful insult (more under voluntary control; such as whimpering cry minutes after a

${ }^{1}$ Department of Psychology, York University; ${ }^{2}$ Department of Psychiatry, The Hospital for Sick Children and University of Toronto, Toronto, Ontario; ${ }^{3}$ Department of Psychology, Dalhousie University and IWK Health Centre, Halifax, Nova Scotia; ${ }^{4}$ Centre for Nursing, The Hospital for Sick Children and Laurence S Bloomberg Faculty of Nursing, University of Toronto, Toronto, Ontario

Correspondence: Dr Rebecca Pillai Riddell, Department of Psychology, York University, 4700 Keele Street, Toronto, Ontario M3J 1 P3.

Telephone 416-736-2100 ext 33204, fax 416-736-5814, e-mail rpr@yorku.ca 
painful stimuli), timing of pain response was also considered important to explore (see Hadistavropolis and Craig [13] for in-depth discussion regarding observational measures of reflexive and voluntary pain reactions during infancy and childhood).

\section{METHODS}

\section{Search strategy}

Only randomized controlled trials (RCTs) and randomized crossover trials ( $\mathrm{RCrTs}$ ) using a no-treatment control group that involved the nonpharmacological management of acute procedural pain in infants and children zero to three years of age were included. No language restrictions were used during the search. Due to the existence of metaanalyses specifically pertaining to circumcision surgery $(14,15)$, sucrose (16), breastfeeding (17) and music (18), these types of studies were excluded from the review.

A unique search strategy for MEDLINE (1966 to April 2011), PsycINFO (1967 to April 2011), EMBASE (1980 to April 2011), and CINAHL (1982 to April 2011) was created in collaboration with three librarians affiliated with the Cochrane Collaboration (online Appendix 1). Completed unpublished trials were located through Dissertation Abstracts International (1980 to 2010), the Cochrane Central Register of Controlled Trials (CENTRAL; Issue 3 2010) on The Cochrane Library and www.clinicaltrials.gov (2010). Appeals were made to pediatric electronic mailing lists (Pain in Child Health [PICH; pich-1@lists.dal.ca], Pediatric Pain [Pediatric-pain@lists.dal. ca], American Psychological Association Division 54 [Pediatric Psychology; div54-members@lists.apa.org]). Finally, the reference lists of recently published reviews were also consulted.

\section{Study selection}

Review authors were not blinded to authors, institutions, journals or results. Using the full-text articles, authors reviewed articles for inclusion (see Acknowledgements). Figure 1 displays the summary of the literature search.

\section{Data extraction}

Data extraction was conducted using a form designed for the present review. Each form also included a risk of bias/quality questionnaire (online Appendix 1). Every included article was extracted independently by at least two authors and compared. When two authors disagreed, the original article and/or the lead author was consulted to achieve consensus.

Qualitative, quantitative, and study quality data were compiled in Excel 2007 (Microsoft Corporation, USA), RevMan 5 or SPSS version 19.0 (SPSS Inc, USA), respectively. A random sampling of $25 \%$ (RevMan5) to 30\% (Excel and SPSS) of all data entered across all three programs was double checked by a subteam of review authors.

Only objectively measured behaviorally-based responses to pain were analyzed (see full review (12) for detailed list of measures included). When studies had more than one unidimensional behavioral pain measure, the most specific measure available was used. For example, pain facial expression was used over cry duration. If multimodal measures were used (ie, measures that provided a total score based on behavioural and physiological measurement or multiple behavioural scales), the total score was used.

\section{Quality and treatment integrity assessment}

Every study included in the present review was scored for quality and treatment integrity by at least two review authors. The Yates Quality of Study Design and Methods Scale (19) was used to develop the study quality rating form for this review, as this scale was specifically validated for nonpharmacological treatments.

Three minor modifications were made to the Yates scale (12). The maximum score on the revised Yates scale was 23 points, with higher scores indicating higher quality (Table 3 for risk of bias scores). See online appendix for the modified measure.

While the majority of studies were deemed of satisfactory-marginal quality, five studies were classified as lower/unknown quality due to receiving a score of 13 or less (20-24).
Treatment integrity was also assessed because almost one-half of the analyzed studies were crossover designs. Two raters independently judged the treatment integrity on five dimensions: treatment adherence, treatment exposure, quality of delivery, participant responsiveness, and program differentiation (25) to arrive at an overall judgment. Only one study had lower/unknown treatment integrity (26).

\section{Data synthesis}

Overall strategy: Three main principles guided the meta-analysis of the data collected for the present review:

1. Certain types of methods had to be excluded to validly pool results. Accordingly, for a treatment study to be included in the metaanalysis, it had to have at least one trial that was an RCT or RCrT that used a no-treatment control group and included a measure that included a behavioural pain outcome. Trials that studied a relevant nonpharmacological treatment that did not meet these requirements were qualitatively described within the review to further contextualize the findings.

2. Studies within the 13 different treatments (Table 3) were first separated into one of three age groups:

Preterm born: infants born at 36 weeks gestation or less.

Neonate full-term: infants born at 37 weeks until one month of age.

Older infant/young child: infants older than one month to 36 months of age. For brevity, this group will be referred to as 'Older infant'.

3. Studies within each age group were then further divided into one of two pain response types:

Pain reactivity: measured within the first $30 \mathrm{~s}$ after the painful stimulus was discontinued.

Immediate pain-related regulation: measured after the first $30 \mathrm{~s}$ post acutely painful stimulus. If multiple measurements were taken after the first 30 s elapsed, the measurement closest to the 30s-time point was used.

\section{Statistical analyses}

Primary analyses: The results from individual studies were pooled using the generic inverse method for a random-effects model in RevMan 5. Using this statistical methodology, an index of the variability of the sample (standard error) and sample size was used to determine how influential each study would be to the final meta-analytic statistic (standardized mean difference [SMD]). A 95\% CI was also reported, which incorporated the standard error of the pooled treatment effect for the treatment effect (ie, SMD). As RCTs and RCrTs were included, different procedures, obtained from a Cochrane statistical consultant, were used. Details of this procedure are presented elsewhere (12). When data were missing, study authors were contacted or recommended techniques for interpolation/estimation from $P$ values, $t$ scores and $F$ scores were used (25).

Secondary analyses: When two or more trials were meta-analyzed in the primary analysis and heterogeneity and/or quality was an issue, secondary sensitivity analyses were conducted. The $\mathrm{I}^{2}$ statistic (27) determined the impact of heterogeneity. When heterogeneity was an issue due to highly variable $\operatorname{SMD}(\mathrm{s})$, analyses were re-run without these studies to examine the impact of the pooled findings. When analyses included a study of lower/unknown quality or treatment integrity, analyses were also re-run without these studies to examine the impact on the pooled findings. Authors' conclusions were based on a synthesis of all three potential analytic steps. Qualitative information from excluded studies were only provided as additional contextual information.

\section{RESULTS}

For the final analysis, 51 trials (3396 participants) were included quantitatively (Table 1) (20-24,26,28-72) and 20 trials (Table 2) (73-92) were qualitatively mentioned. Thirty-five separate primary analyses were run among the 13 interventions, three age groups and two pain response types. Table 3 presents the primary meta-analytic results from 
this review (SMD, 95\% CI and $\mathrm{I}^{2}$ ) and, when applicable, the secondary statistics re-run with studies removed due to heterogeneity and/or study quality.

Of the 3396 participants, 1581 were in treatment conditions only, 1153 were in control conditions and 662 were in a crossover condition. Of the 51 studies, 21 used a cross-over design and 30 used a between-groups design.

The following painful procedures (determined by respective study authors rather than review authors) were included in this review: 29 studies examined treatments for heelstick, 10 studies examined needle-injection procedures, six studies assessed venipuncture, two examined NICU diaper changes, two studies investigated endotracheal suctioning and two studied a neonatal intensive care unit (NICU) weighing procedure.

\section{DISCUSSION}

The summary interpretation of the primary meta-analytic findings, contextualized by secondary heterogeneity and quality/treatment integrity analyses, are presented in Table 4. Based on these results, treatments were assigned a number from 1 to 4 , for each age and pain response type. As will be discussed below, the ratings reflect whether, as the literature currently stands, evidence supported the specific treatment for pain management (efficacy) or did not support the specific treatment for pain management (inefficacy). Each treatment's efficacy or inefficacy was further qualified by the level of support (sufficient versus limited).

Treatment efficacy was denoted by either a 1 (sufficient evidence, ie, two or more quality trials supporting efficacy) or 2 (limited evidence, ie, either due to quality, quantity or heterogeneity of trials, supporting efficacy). Treatment inefficacy was denoted by either a 3 (limited evidence [ie, either due to quality, quantity or trial heterogeneity]) or a 4 (sufficient evidence [ie, two or more quality trials supporting inefficacy]). Blank cells indicate no applicable research for that combination of treatment, age and pain response. A discussion of each of the findings follows.

Kangaroo care (also known as skin-to-skin contact)

An infant is placed on their caregiver's bare chest before, during and after a painful procedure.

Preterm infants: Sufficient evidence suggests kangaroo care is efficacious in reducing pain reactivity and improving immediate painrelated regulation. While there was substantial heterogeneity, secondary analyses confirmed this finding.

Four studies that were excluded from the statistical analyses (73-76) also indirectly support kangaroo care as efficacious in improving pain reactivity and immediate pain-related regulation in preterm infants.

Neonates: Limited evidence suggests that kangaroo care is not efficacious as an intervention for pain reactivity or immediate pain-related regulation. However, heterogeneity undermines our confidence in the pooled results. Given the exposure times in the premature infant literature, future research should explore whether using a longer exposure time in kangaroo care for neonates prior to the painful procedure (ie, $10 \mathrm{~min}$ or longer akin to preterm techniques), could lead to a significant treatment effect.

\section{Swaddling/facilitated tucking}

A swaddled infant is securely wrapped in a blanket to prevent excessive movement. Facilitated tucking is a hand-swaddling technique that holds the infant's extremities flexed and contained.

Preterm infants: There was sufficient evidence to support the use of swaddling/tucking as an efficacious intervention for reducing painrelated distress reactivity and immediate pain-related regulation in preterm infants. Two studies $(74,77)$, that were not included in the analysis due to use of an active control group, suggested that swaddling was as efficacious as containment but not as efficacious as kangaroo care.

Neonates: Limited evidence supports the efficaciousness of swaddling/ tucking related interventions for the healthy neonate.

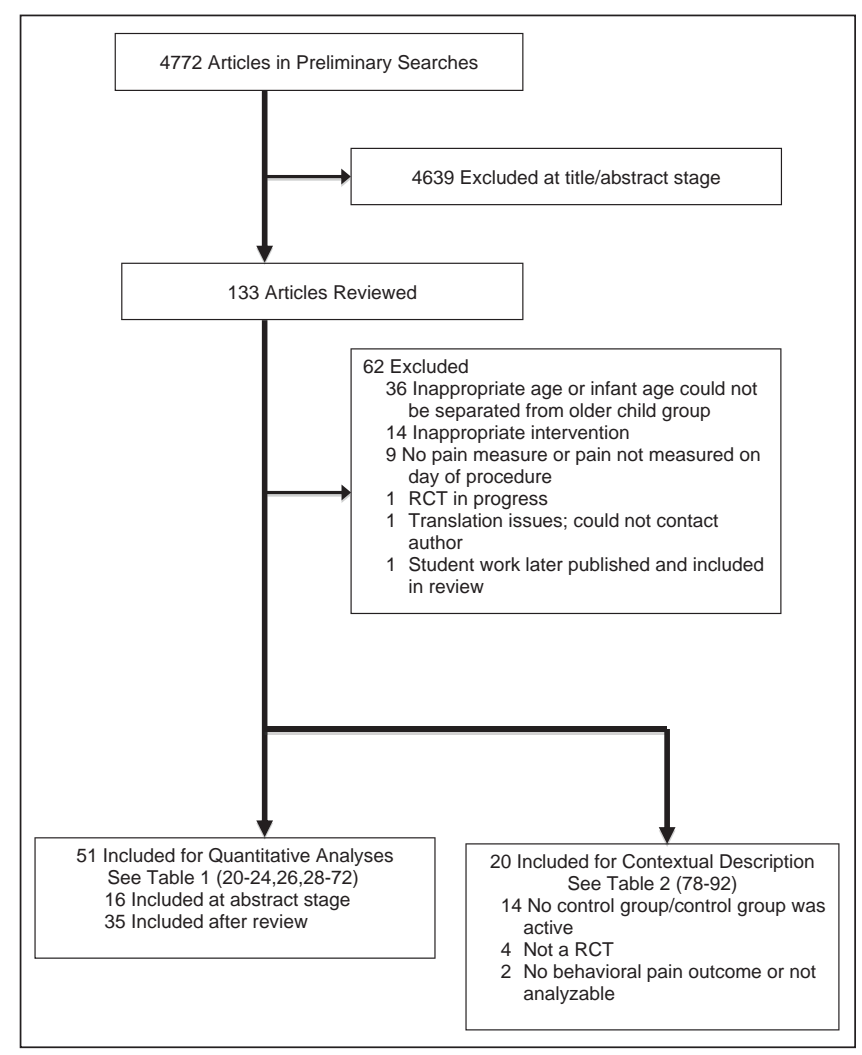

Figure 1) Literature search results. RCT Randomized controlled trial

Non-nutritive sucking-related strategies

An object (eg, pacifier, nonlactating nipple) is placed into an infant's mouth to stimulate orotactile or sucking behaviours during a painful event.

Preterm infants: There is sufficient evidence that sucking is efficacious in reducing pain-related distress reactivity and improving immediate pain-related regulation. Pain relief may be maximized if sucking begins at least $3 \mathrm{~min}$ before the painful stimuli. Two studies that were not included in the analyses due to the use of an active control group $(85,89)$ also suggest that sucking helps diminish pain reactivity.

Neonates: The results show sufficient evidence for sucking to reduce pain reactivity and immediate pain-related regulation. Four studies that were not included due to the exclusion criteria (84-86,91), also lend support to the efficacy of sucking to improve immediate painrelated regulation.

Older infants: Limited evidence suggests that sucking may be an efficacious intervention to improve pain reactivity.

\section{Swallowing water}

Water is administered for ingestion without inciting extensive sucking (eg, water administered by a dropper).

Preterm infants: There was limited evidence that water is an inefficacious intervention for pain reactivity or immediate pain-related regulation for preterm infants.

Neonates: There was limited evidence that water is an inefficacious intervention for pain reactivity or immediate pain-related regulation. Older infants: There was limited evidence that water is an inefficacious intervention for immediate pain-related regulation.

The above studies used 'water' as a treatment arm (comparing them to a 'no-treatment' control), while most other studies in the literature used water as the 'no-treatment' control group. Given the more common use of water in the literature and the limited evidence at every age group of its inefficacy, it is not recommended that further research use water as a treatment arm for young child procedural pain studies. 
TABLE 1

\begin{tabular}{|c|c|c|c|c|c|c|c|c|}
\hline $\begin{array}{l}\text { First author } \\
\text { (reference) }\end{array}$ & Year & Between/crossover & Age & $\begin{array}{l}\text { Sample } \\
\text { size }\end{array}$ & Intervention & Reactivity findings & Regulation findings & $\begin{array}{l}\text { Risk } \\
\text { of } \\
\text { bias } \\
\text { score }\end{array}$ \\
\hline Akcan (29) & 2009 & Between-groups trial & Preterm & 50 & Kangaroo care & - & Supports efficacy & 19 \\
\hline Castral (30) & 2008 & Between-groups trial & Preterm & 59 & Kangaroo care & Supports efficacy & Does not support efficacy & 15 \\
\hline Ferber (31) & 2008 & Crossover trial & Preterm & 29 & Kangaroo care & Supports efficacy & Supports efficacy & 19 \\
\hline Kashaninia (34) & 2008 & Between-groups trial & Neonate & 100 & Kangaroo care & Supports efficacy & - & 16 \\
\hline Gray (35) & 2000 & Between-groups trial & Neonate & 23 & Kangaroo care & - & Supports efficacy & 18 \\
\hline Chermont (36) & 2009 & Between-groups trial & Neonate & 320 & Kangaroo care & Does not support efficacy & Does not support efficacy & 20 \\
\hline Bellieni (37) & 2001 & Crossover trial & Preterm & 17 & Non-nutritive sucking-related & Supports efficacy & - & 15 \\
\hline Liaw (38) & 2010 & Between-groups trial & Preterm & 104 & Non-nutritive sucking-related & Does not support efficacy & Supports efficacy & 22 \\
\hline Yilmaz (42) & 2010 & Between-groups trial & Neonate & 60 & Non-nutritive sucking-related & Does not support efficacy & Supports efficacy & 17 \\
\hline Liu (43) & 2010 & Between-groups trial & Neonate & 70 & Non-nutritive sucking-related & Supports efficacy & Supports efficacy & 18 \\
\hline Curtis (44) & 2007 & Between-groups trial & Older infant & 41 & Non-nutritive sucking-related & - & Supports efficacy & 21 \\
\hline Axelin (45) & 2009 & Crossover trial & Preterm & 20 & Swaddling or tucking & Supports efficacy & - & 21 \\
\hline Comaru (46) & 2009 & Crossover trial & Preterm & 47 & Swaddling or tucking & Supports efficacy & - & 21 \\
\hline Hill (47) & 2005 & Crossover trial & Preterm & 12 & Swaddling or tucking & Supports efficacy & - & 21 \\
\hline Ward-Larson (48) & 2004 & Crossover trial & Preterm & 40 & Swaddling or tucking & Supports efficacy & - & 17 \\
\hline Corff (26) & 1995 & Crossover trial & Preterm & 30 & Swaddling or tucking & - & Supports efficacy & 14 \\
\hline Fearon (49) & 1997 & Crossover trial & Preterm & 15 & Swaddling or tucking & - & Supports efficacy & 20 \\
\hline Axelin (50) & 2006 & Crossover trial & Preterm & 20 & Swaddling or tucking & Supports efficacy & Does not support efficacy & 16 \\
\hline Morrow (51) & 2010 & Between-groups trial & Neonate & 42 & Swaddling or tucking & Supports efficacy & - & 18 \\
\hline Johnston (58) & 2007 & Crossover trial & Preterm & 19 & Maternal voice & Does not support efficacy & - & 17 \\
\hline Carbajal (59) & 2003 & Between-groups trial & Neonate & 90 & Rocking and/or holding & Does not support efficacy & - & 20 \\
\hline Gormally (60) & 2001 & Between-groups trial & Neonate & 41 & Rocking and/or holding & Supports efficacy & Supports efficacy & 14 \\
\hline Ipp (61) & 2004 & Between-groups trial & Older Infant & 106 & Rocking and/or holding & Does not support efficacy & - & 19 \\
\hline Cohen (21) & 2002 & Between-groups trial & Older Infant & 90 & Video distraction & Supports efficacy & - & 10 \\
\hline Cohen (62) & 2006 & Between-groups trial & Older Infant & 126 & Video distraction & - & Supports efficacy & 17 \\
\hline Bustos (63) & 2008 & Between-groups trial & Older Infant & 50 & Structured parent involvement & Does not support efficacy & - & 18 \\
\hline Stevens (64) & 1999 & Crossover trial & Preterm & 122 & $\begin{array}{l}\text { Non-nutritive sucking-related } \\
\text { Swaddling or tucking }\end{array}$ & $\begin{array}{l}\text { Supports efficacy } \\
\text { Does not support efficacy }\end{array}$ & - & 17 \\
\hline \multirow[t]{2}{*}{ Whipple (22) } & 2004 & Between-groups trial & Preterm & 60 & $\begin{array}{l}\text { Non-nutritive sucking-related } \\
\text { (pacifier \& lullaby) }\end{array}$ & - & Supports efficacy & 8 \\
\hline & & & & & $\begin{array}{l}\text { Non-nutritive sucking-related } \\
\text { (pacifier only) }\end{array}$ & - & Supports efficacy & \\
\hline Elserafy (65) & 2009 & Crossover trial & Preterm & 36 & $\begin{array}{l}\text { Non-nutritive sucking-related- } \\
\text { pacifier } \\
\text { Swallowing water } \\
\text { Non-nutritive sucking-related- } \\
\text { pacifier with water }\end{array}$ & $\begin{array}{l}\text { Does not support efficacy } \\
\text { Does not support efficacy } \\
\text { Does not support efficacy }\end{array}$ & $\begin{array}{l}\text { Does not support efficacy } \\
\text { Does not support efficacy } \\
\text { Does not support efficacy }\end{array}$ & 18 \\
\hline \multirow[t]{2}{*}{ Carbajal (66) } & 1999 & Between-groups trial & Neonate & 75 & Swallowing water & Does not support efficacy & - & 22 \\
\hline & & & & & Non-nutritive sucking-related & Supports efficacy & - & \\
\hline \multirow[t]{2}{*}{ Bellieni (67) } & 2002 & Between-groups trial & Neonate & 60 & Non-nutritive sucking-related & Supports efficacy & - & 20 \\
\hline & & & & & Touch or massage & Does not support efficacy & - & \\
\hline
\end{tabular}




\begin{tabular}{|c|c|c|c|c|c|c|c|c|}
\hline $\begin{array}{l}\text { First author } \\
\text { (reference) }\end{array}$ & Year & Between/crossover & Age & $\begin{array}{l}\text { Sam } \\
\text { size }\end{array}$ & Intervention & Reactivity findings & Regulation findings & $\begin{array}{l}\text { Risk } \\
\text { of } \\
\text { bias } \\
\text { score }\end{array}$ \\
\hline \multirow[t]{2}{*}{$\operatorname{Im}(68)$} & 2008 & Between-groups trial & Neonate & 99 & Non-nutritive sucking-related & - & Does not support efficacy & 13 \\
\hline & & & & & Touch or massage & - & Does not support efficacy & \\
\hline \multirow[t]{2}{*}{ Allen (24) } & 1996 & Between-groups trial & Neonate & 34 & Swallowing water & - & Supports efficacy & 7 \\
\hline & & & Older Infant & 30 & & - & Does not support efficacy & \\
\hline \multirow{2}{*}{$\begin{array}{l}\text { Cramer- } \\
\text { Berness (69) }\end{array}$} & 2005 & Between-groups trial & Older Infant & 123 & Toy distraction & Does not support efficacy & - & 18 \\
\hline & & & & & Structured parent involvement & Supports efficacy & - & \\
\hline \multirow{2}{*}{$\begin{array}{l}\text { Cramer- } \\
\text { Berness (70) }\end{array}$} & $2005 b$ & Between-groups trial & Older Infant & 117 & Toy distraction & Does not support efficacy & - & 19 \\
\hline & & & & & Structured parent involvement & Does not support efficacy & - & \\
\hline \multirow[t]{2}{*}{ Bauchner (71) } & 1996 & Between-groups trial & Older Infant & 435 & Parent presence & - & Does not support efficacy & 17 \\
\hline & & & & & Structured parent involvement & - & Does not support efficacy & \\
\hline \multirow{2}{*}{$\begin{array}{l}\text { Hillgrove Stuart } \\
\text { (72) }\end{array}$} & 2008 & Between-groups trial & Older Infant & 99 & Toy distraction - RA & Does not support efficacy & Does not support efficacy & 20 \\
\hline & & & & & Toy distraction - Parent & Does not support efficacy & Does not support efficacy & \\
\hline
\end{tabular}

${ }^{*}$ Dash indicates no research performed for that treatment, age and pain response combination. RA Research assistant

\section{Rocking and/or holding}

An infant is held and/or gently moved up and down or side-to-side by a caregiver.

Neonates: In terms of pain reactivity, rocking/holding was not efficacious in reducing pain reactivity but substantial heterogeneity reduces our confidence. One study, not included due to lack of randomization (89), suggested a significant difference in pain reactivity between infants who were held and control infants. However, there was sufficient evidence to support the efficaciousness of rocking/holding interventions for immediate pain-related regulation.

Older infants: There was limited evidence suggesting rocking/holding is not an efficacious intervention for pain-related distress reactivity in older infants.

\section{Artificial rocking and water}

An infant is placed in a bassinet-type machine that provides a swaying motion. Water is administered via a dropper.

Preterm infants: Limited evidence indicates that simulated rocking and water is not an efficacious intervention for reducing pain-related distress pain reactivity for preterm infants.

\section{Touch/massage/therapeutic touch}

An infant's body (i.e. touch, massage) or energy field (therapeutic touch) is 'stroked' or rubbed to provide some type of counter-stimulation to the nociceptive input.

Preterm infants: Current evidence does not support touch/massagerelated interventions as efficacious in improving the immediate painrelated regulation but caution is warranted given the presence of substantial heterogeneity. One study not included in the analysis due to exclusion criteria (79) demonstrated that massage was more efficacious at reducing preterm infant's heart rate than light pressure or no massage therapy.

Neonates: Limited evidence suggests touch/massage related interventions are not efficacious to reduce pain reactivity or immediate painrelated regulation. One study that was not included in the analysis due to exclusion criteria (78) provides further support to these findings.

Older infants: Limited evidence suggests that therapeutic touch is not efficacious in reducing pain reactivity in older infants.

\section{Environmental modification}

Interventions involved modifying the environment in which an infant experiences painful procedures (ie, low noise and lighting, clustering procedures to avoid over handling, soothing smells).

Preterm infants: While the pooled result from two studies suggest that environmental modification was not efficacious for pain reactivity, this must be interpreted with caution due to substantial heterogeneity. However, there is limited evidence to suggest that environmental modification is efficacious for immediate pain-related regulation.

\section{Toy distraction}

Toy distraction is defined as the use of a toy to divert attention from the painful stimulus.

Older infants: Sufficient evidence suggests that toy distraction is not efficacious for reducing pain-related distress reactivity in older infants. Limited evidence suggests that it is also not efficacious for improving immediate pain-related regulation.

\section{Video distraction}

An audio-visual screen displaying two-dimensional moving images with coordinated audio is used to divert the infants attention from the painful stimulus

Older infants: Limited evidence suggests that video distraction is efficacious in reducing pain-related reactivity. Limited evidence also supports efficacy for improving immediate pain-related regulation.

\section{Structured parental involvement}

Parents are instructed about strategies that are accepted as painreducing but are not given any materials to aid them (eg, rocking, holding, shushing, talking, rubbing, tickling, and distracting attention without toy or video).

Older infants: Structured parent involvement was not found to be efficacious for pain reactivity. However, caution should be applied to this finding as post-hoc heterogeneity analyses contradicted this finding when one outlying study was removed. In addition, one excluded study also suggested that structured parental involvement significantly improved time to regulate post-immunization (90).

\section{Simulated maternal voice}

An infant is exposed to a reproduction of the mother's voice to help simulate the fetal environment.

Preterm infants: Results from one study indicated that mother's voice was not more efficacious than a no-treatment control for reducing pain-related distress reactivity for preterm infants.

\section{Parent presence}

The parent is present during a painful procedure but not interacting extensively with the child in a manner thought to be pain reducing. Older infants: Limited evidence indicates that parent presence is not efficacious for improving immediate pain-related regulation.

\section{Implications for practice}

\section{CONCLUSIONS}

For preterm infants, there was sufficient evidence to recommend kangaroo care, sucking-related interventions, and swaddling/facilitated tucking interventions for both pain reactivity and immediate painrelated regulation. For neonates, there was sufficient evidence to 
TABLE 2

Studies included for further contextual information

\begin{tabular}{|c|c|c|c|c|c|c|}
\hline $\begin{array}{l}\text { First } \\
\text { author } \\
\text { (reference) }\end{array}$ & Year & Age & Intervention & Pain reactivity findings & Pain regulation findings & $\begin{array}{l}\text { Reason for exclusion } \\
\text { from quantitative } \\
\text { analyses }\end{array}$ \\
\hline Cong (73) & 2009 & Preterm & $\begin{array}{l}\text { Facilitated tucking vs non- } \\
\text { nutritive sucking }\end{array}$ & Supports efficacy & - & $\begin{array}{l}\text { No behavioural pain } \\
\text { measure reported }\end{array}$ \\
\hline Johnston (74) & 2008 & Preterm & Kangaroo care & Does not support efficacy & Supports efficacy & Control group was active \\
\hline $\begin{array}{l}\text { Johnston } \\
\text { (75) }\end{array}$ & 2009 & Preterm & Kangaroo care & $\begin{array}{l}\text { No difference between kangaroo care } \\
\text { and enhanced kangaroo care }\end{array}$ & $\begin{array}{l}\text { eNo difference between kangaroo care } \\
\text { and enhanced kangaroo care }\end{array}$ & Control group was active \\
\hline $\begin{array}{l}\text { Ludington- } \\
\text { Hoe (76) }\end{array}$ & 2005 & Preterm & Kangaroo care & Supports efficacy & Supports efficacy & Control group was active \\
\hline Huang (77) & 2004 & Preterm & Kangaroo care & $\begin{array}{l}\text { No difference between swaddling } \\
\text { and containment }\end{array}$ & - & Control group was active \\
\hline Cignacco (78) & 2008 & Preterm & Kangaroo care & $\begin{array}{l}\text { No difference between multisensorial } \\
\text { stimulation and facilitated tucking }\end{array}$ & $\begin{array}{l}\text { I No difference between multisensorial } \\
\text { stimulation and facilitated tucking }\end{array}$ & Control group was active \\
\hline Diego (79) & 2009 & Preterm & Kangaroo care & - & Supports efficacy & Control group was active \\
\hline Goubet (80) & 2003 & Preterm & Smell (familiar vs unfamiliar) & $\begin{array}{l}\text { No difference between familiar and } \\
\text { unfamiliar odour }\end{array}$ & $\begin{array}{l}\text { Familiar odour more efficacious than } \\
\text { unfamiliar odour }\end{array}$ & Control group was active \\
\hline Grunau (81) & 2004 & Preterm & $\begin{array}{l}\text { Multisensorial stimulation vs } \\
\text { facilitated tucking }\end{array}$ & $\begin{array}{l}\text { No difference between prone and } \\
\text { supine positioning }\end{array}$ & - & No control group \\
\hline Vivancos (82) & 2010 & Neonate & Non-nutritive sucking & Does not support efficacy & Does not support efficacy & Not an RCT \\
\hline Okan (83) & 2010 & Neonate & Non-nutritive sucking & Does not support efficacy & Supports efficacy & $\begin{array}{l}\text { No means or SDs } \\
\text { reported; could not } \\
\text { contact author }\end{array}$ \\
\hline Aguirre (84) & 2008 & Neonate & $\begin{array}{l}\text { Non-nutritive sucking vs non- } \\
\text { nutritive sucking \& swaddling }\end{array}$ & $\begin{array}{l}\text { Non-nutritive sucking more } \\
\text { efficacious than facilitated tucking }\end{array}$ & - & Control group was active \\
\hline Bueno (85) & 2010 & Neonate & Pacifier vs swaddling & $\begin{array}{l}\text { No difference between non-nutritive } \\
\text { sucking and non-nutritive sucking } \\
\text { with swaddling }\end{array}$ & $\begin{array}{l}\text { No difference between non-nutritive } \\
\text { sucking and non-nutritive sucking } \\
\text { with swaddling }\end{array}$ & Control group was active \\
\hline Campos (86) & 1989 & Neonate & Positioning (prone vs supine) & $\begin{array}{l}\text { No difference between pacifier and } \\
\text { swaddling }\end{array}$ & $\begin{array}{l}\text { Pacifier more efficacious than } \\
\text { swaddling }\end{array}$ & Control group was active \\
\hline Goubet (87) & 2007 & Neonate & Rocking and/or holding & - & $\begin{array}{l}\text { Familiar odour more efficacious than } \\
\text { unfamiliar odour }\end{array}$ & Control group was active \\
\hline Rattaz (88) & 2005 & Neonate & Smell (familiar vs unfamiliar) & $\begin{array}{l}\text { No difference between familiar and } \\
\text { unfamiliar odour }\end{array}$ & $\begin{array}{l}\text { Familiar odour more efficacious than } \\
\text { unfamiliar odour }\end{array}$ & No control group \\
\hline \multirow{2}{*}{$\begin{array}{l}\text { Weissman } \\
\text { (89) }\end{array}$} & 2009 & Neonate & Smell (familiar vs unfamiliar) & Supports efficacy & - & Not an RCT \\
\hline & & & Smell (familiar vs unfamiliar) & Supports efficacy & - & \\
\hline Felt (90) & 2000 & $\begin{array}{l}\text { Older } \\
\text { Infant }\end{array}$ & $\begin{array}{l}\text { Structured parental } \\
\text { intervention }\end{array}$ & - & Supports Efficacy & Not an RCT \\
\hline \multirow[t]{2}{*}{$\begin{array}{l}\text { Morelius } \\
\text { (91) }\end{array}$} & 2009 & $\begin{array}{l}\text { Older } \\
\text { Infant }\end{array}$ & Swaddling or tucking & - & Does Not Support Efficacy & Not an RCT \\
\hline & & & Swallowing water & - & Does Not Support Efficacy & \\
\hline Ipp (92) & 2009 & $\begin{array}{l}\text { Older } \\
\text { Infant }\end{array}$ & Vaccination order & $\begin{array}{l}\text { Supports injecting DPTAP-Hib } \\
\text { vaccine before PCV }\end{array}$ & - & No control group \\
\hline
\end{tabular}

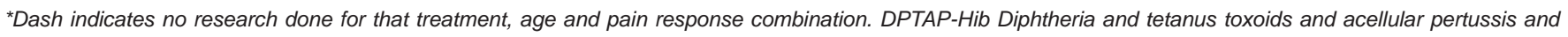
Haemophilus influenza type $b$ vaccine; PCV Pneumococcal conjugated vaccine; RCT Randomized controlled trial

recommend sucking-related interventions as an efficacious treatment for pain reactivity and immediate pain-related regulation. Rocking/holding was also found to be efficacious for neonatal immediate pain-related regulation. For older infants, there were no treatments reviewed that demonstrated sufficient evidence. Overall, due to heterogeneity, some analyses that found a lack of treatment effect need to be interpreted with caution. Finally, while more rigorous research is needed to confirm these findings, environmental modification (preterms), sucking (neonates) and video distraction (older infant/child) have limited evidence supporting efficacy.

\section{Implications for research}

Significant gaps in the existing treatment literature on non pharmacological management of acute pain in infancy have been discerned. Based on established patterns of efficacy in other age groups/pain response types, it would seem especially productive to the field of infant pain management to investigate:
- Kangaroo care for older infants' pain reactivity and immediate pain-related regulation (eg, for the two-month immunization)

- Sucking-related interventions for older infants'/young children's pain reactivity

- Swaddling or tucking-related interventions for older infants pain reactivity and immediate pain-related regulation (eg, two-month immunization)

- Rocking/holding for older infants' immediate pain-related regulation

In addition, preliminary work from other studies (excluded from our overall quantitative analyses for methodological reasons) suggests that more research is needed to explore: exposing an infant to a familiar odor $(80,87,88)$, feeding an infant formula (89) and administering the least painful immunization first (92) as potential nonpharmacological interventions for acute pain. 
TABLE 3

Summary of meta-analyses

\begin{tabular}{|c|c|c|c|c|c|c|}
\hline Treatment & Age group & Pain type & Total, $\mathbf{n}$ & $\begin{array}{l}\text { Effect size } \\
(95 \% \mathrm{Cl})\end{array}$ & $\begin{array}{l}\text { Heterogeneity analysis } \\
(95 \% \mathrm{Cl})\end{array}$ & $\begin{array}{c}\text { Risk of bias analysis } \\
(95 \% \mathrm{Cl})\end{array}$ \\
\hline \multirow[t]{2}{*}{ Kangaroo care } & Preterm & Reactivity & 177 & $-1.12(-2.04$ to -0.21$)$ & $-0.38(-0.65$ to -0.12$)$ & - \\
\hline & & & & $1^{2}=89 \%$ & $\mathrm{I}^{2}=0 \%$ & \\
\hline \multirow[t]{2}{*}{ Kangaroo care } & Preterm & Immediate regulation & 163 & $-0.77(-1.50$ to -0.03$)$ & $-0.45(-0.69$ to -0.20$)$ & - \\
\hline & & & & $1^{2}=82 \%$ & $\mathrm{I}^{2}=0 \%$ & \\
\hline \multirow[t]{2}{*}{ Kangaroo care } & Neonate & Reactivity & 420 & $-0.89(-2.89$ to 1.10$)$ & - & - \\
\hline & & & & $\mathrm{I}^{2}=98 \%$ & & \\
\hline \multirow[t]{2}{*}{ Kangaroo care } & Neonate & Immediate regulation & 343 & $-0.66(-1.73$ to 0.42$)$ & - & - \\
\hline & & & & $l^{2}=82 \%$ & & \\
\hline \multirow[t]{2}{*}{ Swaddling/tucking } & Preterm & Reactivity & 261 & $-0.97(-1.63$ to -0.31$)$ & $-0.90(-1.22$ to -0.59$)$ & - \\
\hline & & & & $1^{2}=88 \%$ & $I^{2}=0 \%$ & \\
\hline \multirow[t]{2}{*}{ Swaddling/tucking } & Preterm & Immediate regulation & 65 & $-0.75(-1.14$ to -0.36$)$ & - & $-0.61(-1.12$ to -0.11$)$ \\
\hline & & & & $1^{2}=0 \%$ & & $\mathrm{I}^{2}=0 \%$ \\
\hline Swaddling/tucking & Neonate & Reactivity & 42 & $-1.26(-1.92$ to -0.60$)$ & - & - \\
\hline \multirow[t]{2}{*}{ Non-nutritive sucking } & Preterm & Reactivity & 305 & $-0.42(-0.68$ to -0.15$)$ & $-0.32(-0.05$ to -0.15$)$ & - \\
\hline & & & & $\mathrm{I}^{2}=48 \%$ & $\mathrm{I}^{2}=0 \%$ & \\
\hline \multirow[t]{2}{*}{ Non-nutritive sucking } & Preterm & Immediate regulation & 226 & $-0.38(-0.59$ to -0.17$)$ & - & $-0.36(-0.59$ to -0.13$)$ \\
\hline & & & & $\mathrm{I}^{2}=0 \%$ & & $\mathrm{I}^{2}=0 \%$ \\
\hline \multirow[t]{2}{*}{ Non-nutritive sucking } & Neonate & Reactivity & 220 & $-1.45(-2.34$ to -0.57$)$ & $-1.88(-2.25$ to -1.50$)$ & - \\
\hline & & & & $\mathrm{I}^{2}=88 \%$ & $I^{2}=0 \%$ & \\
\hline \multirow[t]{2}{*}{ Non-nutritive sucking } & Neonate & Immediate regulation & 325 & $-0.90(-1.54$ to -0.25$)$ & - & $-0.51(-0.91$ to -0.29$)$ \\
\hline & & & & $\mathrm{I}^{2}=84 \%$ & & $\mathrm{I}^{2}=11 \%$ \\
\hline Non-nutritive sucking & Older infants & Immediate regulation & 41 & $-0.89(-1.53$ to -0.25$)$ & - & - \\
\hline Swallowing water & Preterm & Reactivity & 36 & $-0.24(-0.71$ to 0.23$)$ & - & - \\
\hline Swallowing water & Preterm & Immediate regulation & 36 & $-0.23(-0.70$ to 0.24$)$ & - & - \\
\hline Swallowing water & Neonate & Reactivity & 50 & $0.10(-0.45$ to 0.66$)$ & - & - \\
\hline Swallowing water & Neonate & Immediate regulation & 34 & $-0.53(-1.21$ to 0.16$)$ & - & - \\
\hline Swallowing water & Older infants & Immediate regulation & 30 & $0.00(-0.72$ to 0.72$)$ & - & - \\
\hline \multirow[t]{2}{*}{ Rocking/holding } & Neonate & Reactivity & 131 & $-0.33(-1.05$ to 0.39$)$ & - & - \\
\hline & & & & $\mathrm{I}^{2}=73 \%$ & & \\
\hline \multirow[t]{2}{*}{ Rocking/holding } & Neonate & Immediate regulation & 81 & $-0.75(-1.20$ to -0.30$)$ & - & - \\
\hline & & & & $I^{2}=0 \%$ & & \\
\hline Rocking/holding & Older infants & Reactivity & 106 & $0.23(-0.15$ to 0.62$)$ & - & - \\
\hline Simulated rocking + water & Preterm & Reactivity & 44 & $0.00(-0.59$ to 0.59$)$ & - & - \\
\hline \multirow[t]{2}{*}{ Touch or massage } & Preterm & Immediate regulation & 34 & $-0.71(-2.33$ to 0.90$)$ & - & - \\
\hline & & & & $\mathrm{I}^{2}=86 \%$ & & \\
\hline Touch or massage & Neonate & Reactivity & 40 & $-0.30(-0.92$ to 0.32$)$ & - & - \\
\hline Touch or massage & Neonate & Immediate regulation & 66 & $-0.24(-0.73$ to 0.24$)$ & - & - \\
\hline Touch or massage & Older infants & Reactivity & 20 & $-0.21(-0.84$ to 0.41$)$ & - & - \\
\hline \multirow[t]{2}{*}{ Environment modification } & Preterm & Reactivity & 64 & $-6.44(-17.13$ to 4.26$)$ & - & - \\
\hline & & & & $I^{2}=97 \%$ & & \\
\hline Environment modification & Preterm & Immediate regulation & 45 & $-4.01(-5.26$ to -2.77$)$ & - & - \\
\hline \multirow[t]{2}{*}{ Toy distraction } & Older infants & Reactivity & 259 & $-0.10(-0.35$ to 0.14$)$ & - & - \\
\hline & & & & $\mathrm{I}^{2}=0 \%$ & & \\
\hline \multirow[t]{2}{*}{ Toy distraction } & Older infants & Immediate regulation & 133 & $-0.08(-0.50$ to 0.33$)$ & - & - \\
\hline & & & & $\mathrm{I}^{2}=0 \%$ & & \\
\hline Video distraction & Older infants & Reactivity & 90 & $-0.70(-1.13$ to -0.27$)$ & - & - \\
\hline Video distraction & Older infants & Immediate regulation & 126 & $-0.84(-1.20$ to -0.47$)$ & - & - \\
\hline \multirow{2}{*}{$\begin{array}{l}\text { Structured parent } \\
\text { involvement }\end{array}$} & Older infants & Reactivity & 209 & $-0.26(-0.70$ to 0.17$)$ & $-0.49(-0.83$ to -0.14$)$ & - \\
\hline & & & & $\mathrm{I}^{2}=60 \%$ & $\mathrm{I}^{2}=0 \%$ & \\
\hline $\begin{array}{l}\text { Structured parent } \\
\text { involvement }\end{array}$ & Older infants & Immediate regulation & 288 & $0.02(-0.21$ to 0.25$)$ & - & - \\
\hline Mother's voice & Preterm & Reactivity & 19 & $-0.29(-0.94$ to 0.35$)$ & - & - \\
\hline Parent present & Older infants & Immediate regulation & 278 & $0.00(-0.24$ to 0.23$)$ & - & - \\
\hline
\end{tabular}

${ }^{*}$ Dash indicates no research performed for that treatment, age and pain response combination 


\section{TABLE 4}

\section{Summary conclusions}

\begin{tabular}{|c|c|c|c|c|c|c|}
\hline \multirow[b]{2}{*}{ Treatment arm } & \multicolumn{2}{|c|}{ Preterm infants } & \multicolumn{2}{|r|}{ Neonates } & \multicolumn{2}{|c|}{ Older infants } \\
\hline & Reactivity & Immediate regulation & Reactivity & Immediate regulation & Reactivity & Immediate regulation \\
\hline Kangaroo care & 1 & 1 & 3 & 3 & - & - \\
\hline Non-nutritive sucking-related & 1 & 1 & 1 & 1 & - & 2 \\
\hline Swaddling/tucking-related & 1 & 1 & 2 & - & - & - \\
\hline Touch or massage-related & - & 3 & 3 & 3 & 3 & - \\
\hline Environment modification & 3 & 2 & - & - & - & - \\
\hline Simulated rocking and water & 3 & - & - & - & - & - \\
\hline Simulated mother's voice & 3 & - & - & - & - & - \\
\hline Swallowing water & 3 & 3 & 3 & 3 & - & 3 \\
\hline Rocking or holding & - & - & 3 & 1 & 3 & - \\
\hline Toy distraction & - & - & - & - & 4 & 3 \\
\hline Video distraction & - & - & - & - & 2 & 2 \\
\hline Parent present & - & - & - & - & - & 3 \\
\hline Structured parent involvement & - & - & - & - & 3 & 3 \\
\hline
\end{tabular}

1 Sufficient evidence supports efficacy for reducing pain-related behaviours (support of two or more trials); 2 Limited evidence suggests efficacy for reducing painrelated behaviours (eg, support of one trial or heterogeneity among trials); 3 Limited evidence suggests inefficacy for reducing pain-related behaviours (eg, support of one trial or heterogeneity among trials); 4 Sufficient evidence supports inefficacy for reducing pain-related behaviours (support of one or more trials). Dash indicates no research performed for that treatment, age and pain response combination

It is also important to note that certain treatments were grouped together based on similar mechanisms of action despite not being the same treatment (eg, swaddling and tucking, non-nutritive sucking related strategies), which was supported by our heterogeneity analyses. However, with more research, future revisions may be able to report SMDs and CIs separately for treatments encompassed within these groups.

Moreover, given the frequency of immunization during the first years of life, it was disheartening that there were no efficacious nonpharmacological treatments for the older infant/young child. Although there is a substantial evidence base for pharmacological strategies such as sucrose and topical anaesthetics (93), from an economic and pragmatic perspective, it would behoove researchers to spend more resources in investigating efficacious nonpharmacological pain management for older infants.

The lack of developmentally-informed work on parent-mediated interventions was also a cause for a concern. Over the first years of life, it has been argued (94) that the caregiver is the most important context for the infant in pain. Currently, studies that have attempted to formally structure parent behaviour have been limited and, thus, shown to be ineffective. More work on improved parent interventions, especially ones that capitalize on an infant's primary need for proximity to the parent during periods of distress (95), is needed. Teaching a parent how to soothe more efficaciously their infant or young child in acute pain is a simple, low-cost intervention that is not being used to its potential in today's acute pain context.

In conclusion, while a number of non pharmacological treatments have a sufficient body of evidence supporting their use with preterm infants and to a lesser extent, healthy neonates, more research is needed to create a sound repertoire of empirically-supported nonpharmacological treatments for procedural pain in older infants/young children.

ACKNOWLEDGEMENTS: This work is a brief summary of a review created for the Cochrane Collaboration. The full review can be found at Cochrane Database of Systematic Reviews 2011, Issue 10. Art. No.: CD006275. DOI:10.1002/146517858.CD006275.pub2. Dr Pillai Riddell and Ms Racine had full access to all of the data in the study and take responsibility for the integrity of the data and the accuracy of the data analysis.

No authors have potential conflicts of interest, including financial, activities, relationships, and affiliations. Funding sources, in the form of salary support to one or more authors, included Canadian Institutes of Health Research, Social Sciences and Humanities Research Council, Ontario Graduate Scholarship Program, Lillian Wright Foundation and the Signy Hildur Chair in Pediatric Nursing. None of these organizations had input regarding the design and conduct of the study; collection, management, analysis, and interpretation of the data; and preparation, review, nor final approval of the manuscript.

Ms Alanna Gerwitz-Stern contributed to the initial stages of the full Cochrane review and was listed as an author on that work. Ms Jennifer Lyons entered data into data management software and was paid by Dr Pillai Riddell. Ms Grace Lee and Ms Janet Yamada extracted data from three articles and were financially compensated by Dr Stevens.

Rebecca Pillai Riddell PhD: Study selection, article extraction, data analysis, data interpretation, manuscript preparation, and manuscript review Nicole Racine MA: Study selection, article extraction, data checking, data analysis, data interpretation, and manuscript review. Kara Turcotte BA: Study selection, article extraction, data checking, data interpretation, and manuscript review. Lindsay Uman PhD: Study selection, article extraction, data interpretation, and manuscript review. Rachel Horton MA: Article extraction, data interpretation, and manuscript review. Laila Din Osmun MA: Article extraction, data interpretation, and manuscript review. Sara Ahola Kohut MA: Article extraction, data interpretation, and manuscript review. Jessica Hillgrove Stuart MA: Article extraction, data interpretation, and manuscript review. Bonnie Stevens RN, PhD, FCAHS: Data interpretation, manuscript review. Diana Lisi BA: Study selection, data checking, data interpretation, manuscript review. Source of support: Discretionary funds to Dr Pillai Riddell from York University.

Co-publication with the Cochrane Collaboration: Pillai Riddell RR, Racine NM, Turcotte K, Uman LS, Horton RE, Din Osmun L, Ahola Kohut S, Hillgrove Stuart J, Stevens B, Gerwitz-Stern A. Nonpharmacological management of infant and young child procedural pain. Cochrane Database of Systematic Reviews 2011, Issue 10. Art. No.: CD006275. DOI:10.1002/146517858.CD006275.pub2

FUNDING SOURCES: York University, Canadian Institutes of Health Research, Social Sciences and Humanities Research Council, Ontario Graduate Scholarship Program, Lillian Wright Foundation and the Signy Hildur Chair in Pediatric Nursing. 


\section{REFERENCES}

1. Field T. Infancy is not without pain. In: Vasta R, ed. Annals of Child Development: A research annual. 1995;10:1-26.

2. Johnston CC, Stevens B, Craig KD, Grunau RV. Developmental changes in pain expression in premature, full-term, two and fourmonth-old infants. Pain 1993;52:201-208.

3. Berde CB, Jaksic T, Lynn AM, Maxwell LG, Soriano SG, Tibboel D. Anaesthesia and analgesia during and after surgery in neonates. Clin Ther 2005;27:900-21.

4. Fitzgerald M. The development of nociceptive circuits. Nat Rev Neurosci 2005;6:507-20.

5. Slater R, Cornelissen L, Fabrizi L, Patten D, Yoxen J, Worley A. Oral sucrose as an analgesic drug for procedural pain in newborn infants: A randomized controlled trial. Lancet 2010;376:1225-32.

6. Grunau R, Craig KD. Pain expression in neonates: Facial action and cry. Pain 1987;28:395-410.

7. Taddio A, Appleton M, Bortolussi R, et al. Reducing the pain of childhood vaccination: An evidence-based clinical practice guidelines (summary). CMAJ 2010;182:1-7

8. Cignacco E, Hamers JPH, Stoffel L, et al. The efficacy of nonpharmacological interventions in the management of procedural pain in preterm and term neonates. A systematic literature review. Eur J Pain 2007;11:139-52.

9. Schechter NL, Zempsky WT, Cohen LL, McGrath PJ, McMurtry CM, Bright NS. Pain reduction during pediatric immunizations: Evidence-based review and recommendations. Pediatrics 2007;119:184-98.

10. Johnston CC, Fernandes AM, Campbell-Yeo M. Pain in neonates is different. Pain 2011;152(3 Suppl):S65-S73.

11. Stevens BJ, Abbott LK, Yamada J, et al. Epidemiology and management of painful procedures in children in Canadian hospitals. CMAJ 2011; 183;E403-10.

12. Pillai Riddell RR, Racine NM, Turcotte K, et al. Non-pharmacological management of infant and young child procedural pain. Cochrane Database Syst Rev 2011. (In press)

13. Hadistavropolis T, Craig K. A theoretical framework for understanding self-report and observational measures of pain: A communications model. Beh Res Ther 2002:40:551-70.

14. Brady-Fryer B, Wiebe N, Lander JA. Pain relief for neonatal circumcision [Review]. Cochrane Database Syst Rev 2009; (1):CD004217.

15. Cyna AM, Middleton P. Caudal epidural block versus other methods of postoperative pain relief for circumcision in boys. Cochrane Database Syst Rev 2010;(11):CD003005.

16. Stevens B, Yamada J, Ohlsson A. Sucrose for analgesia in newborn infants undergoing painful procedures (Updated Cochrane Review). Cochrane Database Syst Rev 2010;(1):CD001069.

17. Shah PS, Aliwalas LL, Shah V. Breastfeeding or breast milk for procedural pain in neonates. Cochrane Database Syst Rev 2009; (1): CD004950.

18. Cepeda MS, Carr DB, Lau J, Alvarez H. Music for pain relief. Cochrane Database Syst Rev 2006;(2):CD004843.

19. Yates SL, Morley S, Eccleston C, de C Williams AC. A scale for rating the quality of psychological trials for pain. Pain 2005;117:314-25.

20. Greenberg CS. A sugar-coated pacifier reduces procedural pain in newborns. Pediatr Nurs 2002;28:271-7.

21. Cohen LL. Reducing infant immunization distress through distraction. Health Psychol 2002;21:207-11.

22. Whipple J. The effect of music-reinforced nonnutritive sucking on state of preterm, low birthweight infants experiencing heelstick (unpublished doctoral dissertation). Tallahassee:

The Florida State University, November 2004.

23. Campos RG. Rocking and pacifiers: Two comforting interventions for heelstick pain. Res Nurs Health 1994;17:321-31.

24. Allen KD, White DD, Walburn JN. Sucrose as an analgesic agent for infants during immunization injections. Arch Pediatr Adolesc Med $1996 ; 150: 270-4$.

25. Higgins JPT, Green S, eds. Cochrane Handbook for Systematic Reviews of Interventions Version 5.1.0. [updated March 2011]. Cochrane Collaboration; 2011. <www.cochrane-handbook.org> (Accessed on April 29, 2011).

26. Corff KE, Seideman R, Venkataraman PS, Lutes L, Yates B. Facilitated tucking: A nonpharmacologic comfort measure for pain in preterm neonates. J Obstet Gynecol Neonatal Nurs 1995;24:143-7.

27. Deeks JJ, Higgins JPT, Altman DG. Analysing and presenting results. In: Higgins JPT, Green S, eds. Cochrane Handbook for
Systematic Reviews of Interventions 4.2.5. [updated May 2005]; section 8. In: The Cochrane Library. Chichester: John Wiley \& Sons, 2005;97-165.

28. de Sousa Freire NB, Santos Garcia JB, Carvahlo Lamy Z. Evaluation of analgesic effect of skin-to-skin contact compared to oral glucose in preterm neonates. Pain 2008;139:28-33.

29. Akcan E, Yigit R, Atici A. The effect of kangaroo care on pain in premature infants during invasive procedures. Turk J Pediatr 2009;51:14-18.

30. Castral TC, Warnock F, Leite AM, Haas VJ, Scochi CGS. The effects of skin-to-skin contact during acute pain in preterm newborns. Eur J Pain 2008;12:464-71.

31. Ferber SG, Makhoul IR. Neurobehavioral assessment of skin-to-skin effects on reaction to pain in preterm infants: A randomized, controlled within-subject trial. Acta Paediatr 2008;97:171-6.

32. Johnston CC, Stevens B, Pinelli J, et al. Kangaroo care is effective in diminishing pain response in preterm neonates. Arch Pediatr Adolesc Med 2003;157:1084-8.

33. Kostandy RR, Ludington-Hoe SM, Cong X, et al. Kangaroo care (skin contact) reduces crying response to pain in preterm neonates: Pilot results. Pain Manag Nurs 2008;9:55-65.

34. Kashaninia Z, Sajedi F, Rahgozar M, Noghabi FA. The effect of kangaroo care on behavioral responses to pain of an intramuscular injection in neonates. J Spec Pediatr Nurs 2008;13:275-80.

35. Gray L, Watt L, Blass EM. Skin-to-skin contact is analgesic in healthy newborns. Pediatrics. January 2000;105:e14.

36. Chermont AG, Falcao LFM, de Souza Silva EHL, de Cassia Xavier Balda R, Guinsburg R. Skin-to-skin contact and/or oral $25 \%$ dextrose for procedural pain relief for term newborn infants. Pediatrics 2009;124:e1101-7.

37. Bellieni CV, Buonocore G, Nenci A, Franci N, Cordelli DM, Bagnoli F. Sensorial saturation: An effective analgesic tool for heelprick in preterm infants. Biol Neonate 2001;80:15-8.

38. Liaw J, Yang L, Ti Y, Tucker Blackburn S, Chang Y, Sun L. Non-nutritive sucking relieves pain for preterm infants during heel stick procedures in Taiwan. J Clin Nurs 2010;19:2741-51.

39. Corbo MG, Mansi G, Stagni A, et al. Nonnutritive sucking during heelstick procedures decreases behavioral distress in the newborn infant. Biol Neonate 2000;77:162-7.

40. Bo KL, Callaghan P. Soothing pain-elicited distress in Chinese neonates. Pediatrics 2000;105:E49.

41. Blass EM, Watt LB. Suckling- and sucrose-induced analgesia in human newborns. Pain 1999;83:611-23

42. Yilmaz F, Arikan D. The effects of various interventions to newborns on pain and duration of crying. J Clin Nurs 2011;20:1008-17.

43. Liu MF, Lin KC, Chou YH, Lee TY. Using non-nutritive sucking and oral glucose solution with neonates to relieve pain: A randomised controlled trial. J Clin Nurs June 2010;19:1604-11.

44. Curtis SJ, Jou H, Ali S, Vandermeer B, Klassen T. A randomized controlled trial of sucrose and/or pacifier as analgesia for infants receiving venipuncture in a pediatric emergency department. BMC Pediatr 2007;7:27

45. Axelin A, Salantera S, Kirjavainen J, Lehtonen L. Oral glucose and parental holding preferable to opioid in pain management in preterm infants. Clin J Pain 2009;25:138-45.

46. Comaru T, Miura E. Postural support improves distress and pain during diaper change in preterm infants. J Perinatol 2009;29:504-7.

47. Hill S, Engle S, Jorgensen J, Kralik A, Whitman K. Effects of facilitated tucking during routine care of infants born preterm. Pediatr Phys Ther 2005; 17:158-63.

48. Ward-Larson C, Horn RA, Gosnell F. The efficacy of facilitated tucking for relieving procedural pain of endotracheal suctioning in very low birthweight infants. MCN Am J Matern Child Nurs 2004;29:151-6.

49. Fearon I, Kisilevsky BS, Hains SM, Muir DW, Tranmer J. Swaddling after heel lance: Age-specific effects on behavioral recovery in preterm infants. J Dec Behav Pediatr 1997;18:222-32.

50. Axelin A, Salantera S, Lehtonen L. Facilitated tucking by parents in pain management of preterm infants - a randomized crossover trial. Early Hum Dev 2006;82:241-7.

51. Morrow C, Hidinger A, Wilkinson-Faulk D. Reducing neonatal pain during routine heel lance procedures. MCN Am J Matern Child Nurs 2010;35:346-54. 
52. Herrington CJ. Reducing pain of heelstick in premature infants with gentle human touch (unpublished doctoral dissertation). ETD Collection: Wayne State University. January 2007: AAI3295977.

53. Jain S, Kumar P, McMillan DD. Prior leg massage decreases pain responses to heel stick in preterm babies. J Pediatr Child Health 2006;42:505-8.

54. Kozub ML. The effect of therapeutic touch on pain response in infants receiving injections (unpublished MSN dissertation). Ohio: Medical College of Ohio at Toledo, August 2001.

55. Sizun J, Ansquer H, Browne J, Tordjman S, Morin JF. Developmental care decreases physiologic and behavioral pain expression in preterm neonates. J Pain 2002;3:446-50.

56. Catelin C, Tordjman S, Morin V, Oger E, Sizun J. Clinical, physiologic, and biologic impact of environmental and behavioral interventions in neonates during a routine nursing procedure. J Pain 2005;6:791-7.

57. Johnston CC, Stremler RL, Stevens BJ, Horton LJ. Effectiveness of oral sucrose and simulated rocking on pain response in preterm neonates. Pain 1997;72:193-9.

58. Johnston CC, Filion F, Nuyt AM. Recorded maternal voice for preterm neonates undergoing heel lance. Adv Neonatal Care 2007;7:258-66.

59. Carbajal R, Veerapan S, Couderc S, Jugie M, Ville Y. Analgesic effect of breast feeding in term neonates: randomised controlled trial. BMJ 2003;326:13.

60. Gormally S, Barr RG, Wertheim L, Alkawaf R, Calinoiu N, Young SN Contact and nutrient caregiving effects on newborn infant pain responses. Dev Med Child Neurol 2001;43:28-38.

61. Ipp M, Taddio A, Goldbach M, Ben David S, Stevens B, Koren G. Effects of age, gender and holding on pain response during infant immunization. Can J Clin Pharmacol 2004;11:e2-7.

62. Cohen LL, MacLaren JE, Fortson BL, et al. Randomized clinical trial of distraction for infant immunization pain. Pain 2006;125:165-71.

63. Bustos T, Jaaniste T, Salmon K, Champion GD. Evaluation of a brief parent intervention teaching coping-promoting behavior for the infant immunization context: A randomized controlled trial. Behav Modif 2008;32:450-67.

64. Stevens B, Johnston C, Franck L, Petryshen P, Jack A, Foster G. The efficacy of developmentally sensitive interventions and sucrose for relieving procedural pain in very low birth weight neonates. Nurs Res 1999;48:35-43.

65. Elserafy FA, Alsaedi SA, Louwrens J, Bin Sadiq B, Mersal AY. Oral sucrose and a pacifier for pain relief during simple procedures in preterm infants: a randomized controlled trial. Ann Saudi Med 2009;29:184-8.

66. Carbajal R, Chauvey X, Couderc S, Olivier-Martin M. Randomised trial of analgesic effects of sucrose, glucose, and pacifiers in term neonates. BMJ 1999;319:1393-7.

67. Bellieni CV, Bagnoli F, Perrone S, et al. Effect of multisensory stimulation on analgesia in term neonates: a randomized controlled trial. Pediatr Res 2002;51:460-3.

68. Im H, Kim E, Park E, Sung K, Oh W. Pain reduction of heel stick in neonates: Yakson compared to non-nutritive sucking. J Trip Pediatr 2008;54:31-5.

69. Cramer-Berness LJ, Friedman AG. Behavioral interventions for infant immunizations. Child Health Care 2005;34:95-111.

70. Cramer-Berness LJ. A comparison of behavioral interventions for infant immunizations. (Doctoral dissertation). New York: State University of New York at Binghamton. 2005;AAT3203883.

71. Bauchner H, Vinci R, Bak S, Pearson C, Corwin MJ. Parents and procedures: A randomized controlled trial. Pediatrics. 1996;98:861-7.

72. Hillgrove Stuart J, Pillai Riddell R. Distraction as a pain management strategy for infants. (Unpublished master's thesis). 2008.

73. Cong X, Ludington-Hoe SM, McCain G, Fu P. Kangaroo care modifies preterm infant heart rate variability in response to heel stick pain: Pilot study. Early Hum Dev 2009;85:561-7.
74. Johnston CC, Filion F, Campbell-Yeo M, et al. Kangaroo mother care diminishes pain from heel lance in very preterm neonates. A crossover trial. BMC Pediatr 2008;8:13.

75. Johnston CC, Filion F, Campbell-Yeo M, et al. Enhanced kangaroo mother care for heel lance in preterm neonates: A crossover trial. J Perinatol 2009;29:51-6.

76. Ludington-Hoe SM, Hosseini R, Torowicz DL. Skin-to-skin contact (kangaroo care) analgesia for preterm infant heel stick. AACN Clin Issues 2005;16:373-87.

77. Huang CM, Tung WS, Kuo LL, Ying-Ju C. Comparison of pain responses of premature infants to the heelstick between containment and swaddling. J Nurs Res 2004;12:31-40.

78. Cignacco E, Hamers JP, Van Lingen RA, et al. Pain relief in ventilated preterm infants during endotracheal suctioning: A randomized controlled trial. Swiss Med Wkly 2008;138:635-45.

79. Diego MA, Field T, Hernandez-Reif M. Procedural pain heart rate responses in massaged preterm infants. Infant Behav Dev 2009;32:226-9.

80. Goubet N, Rattaz C, Pierrat V, Bullinger A, Lequien P. Olfactory experience mediates response to pain in preterm newborns. Dev Psychobiol 2003;42:171-80.

81. Grunau RE, Linhares MB, Holsti L, Oberlander TF, Whitfield MF. Does prone or supine position influence pain responses in preterm infants at 32 weeks gestational age? Clin J Pain 2004;20:76-82.

82. Vivancos RBZ, Leite AM, Scochi CGS, dos Santos CB. The skin to skin contact at birth and newborn crying during vaccination against hepatitis B. [O cantata pele a pele ao nascimento e o choro de recem-nascidos durante vacinacao contra Hepatite B]. Acta Paul Enferm 2010;23:461-5.

83. Okan F, Ozdil A, Bulbul A, Yapici Z, Nuhoglu A. Analgesic effects of skin-to-skin contact and breastfeeding in procedural pain in healthy term neonates. Ann Trop Paediatr 2010;30:119-28.

84. Aguirre Unceta-Barrenechea A, Saitua Iturriaga G, Sainz de Rozas Aparicio I, Riveira Fernandez D. Analgesia when taking heel-lance blood in the newborn. Anales de Pediatria 2008;69:544-47.

85. Bueno M, Bussotti E, DaSilva A, Leao E. Non nutritive sucking and swaddling for pain relief in term neonates. Abstract from the 8th International Symposium on Pediatric Pain, Acapulco, Mexico. March 7 to $11,2010$.

86. Campos RG. Soothing pain-elicited distress with swaddling and pacifiers in early infancy. Child Dev 1989;60:781-92.

87. Goubet N, Strasbaugh K, Chesney J. Familiarity breeds content? Soothing effect of a familiar odor on full-term newborns. J Dev Behav Pediatr June 2007;28:189-94.

88. Rattaz C, Goubet N, Bullinger A. The calming effect of a familiar odor on full-term newborns. J Dev Behav Pediatr 2005;26:86-92.

89. Weissman A, Aranovitch M, Blazer S, Zimmer EZ. Heel-lancing in newborns: Behavioral and spectral analysis assessment of pain control methods. Pediatrics 2009;124:921-6.

90. Felt BT, Mollen E, Diaz S, et al. Behavioral interventions reduce infant distress at immunization. Arch Pediatr Adolesc Med 2000;154:719-24.

91. Morelius E, Theodorsson E, Nelson N. Stress at three-month immunization: parents' and infants' salivary cortisol response in relation to the use of pacifier and oral glucose. Eur J Pain 2009;13:202-8

92. Ipp M, Parkin PC, Lear N, Goldbach M, Taddio A. Order of vaccine injection and infant pain response. Arch Pediatr Adolesc Med 2009;163:469-72.

93. Taddio A, Illersich AL, Ipp M, Kikuta A, Shah V; HELPinKIDS Team. Physical interventions and injection techniques for reducing injection pain during routine childhood immunizations: Systematic review of randomized controlled trials and quasi-randomized controlled trials. Clin Ther 2009;31(Suppl 2): S48-S76.

94. Pillai Riddell R, Racine N. Assessing pain in infancy: The caregiver context. Pain Res Manag 2009;14:27-32.

95. Bowlby J. Attachment, 2nd edn. USA: Tavistock Institute of Human Relations; 1969/1982. 


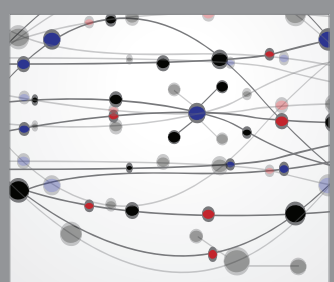

The Scientific World Journal
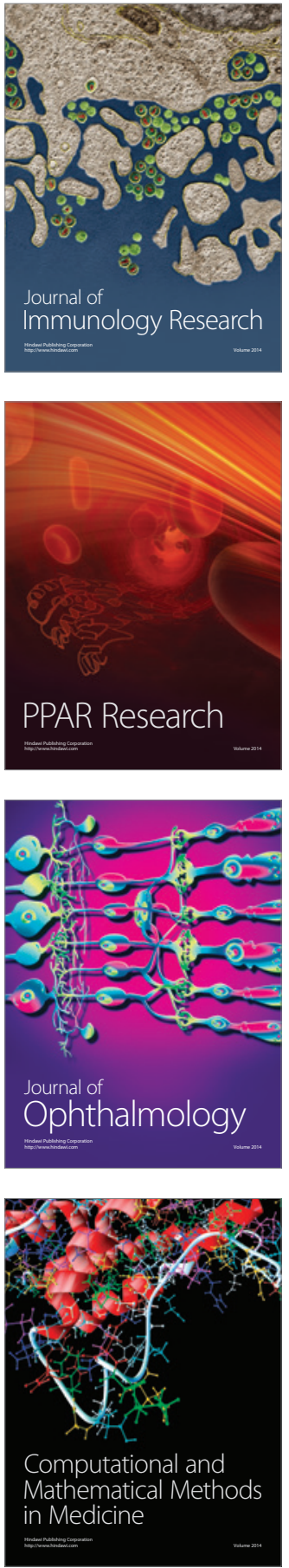

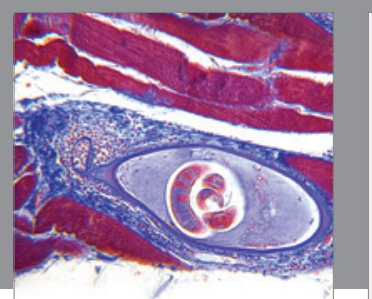

Gastroenterology Research and Practice

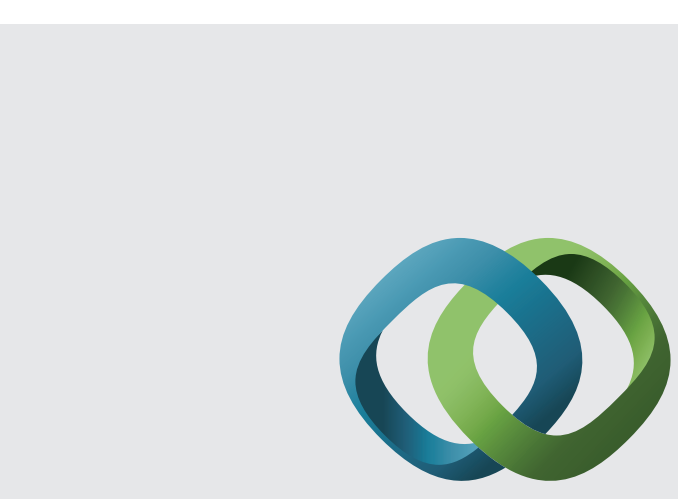

\section{Hindawi}

Submit your manuscripts at

http://www.hindawi.com
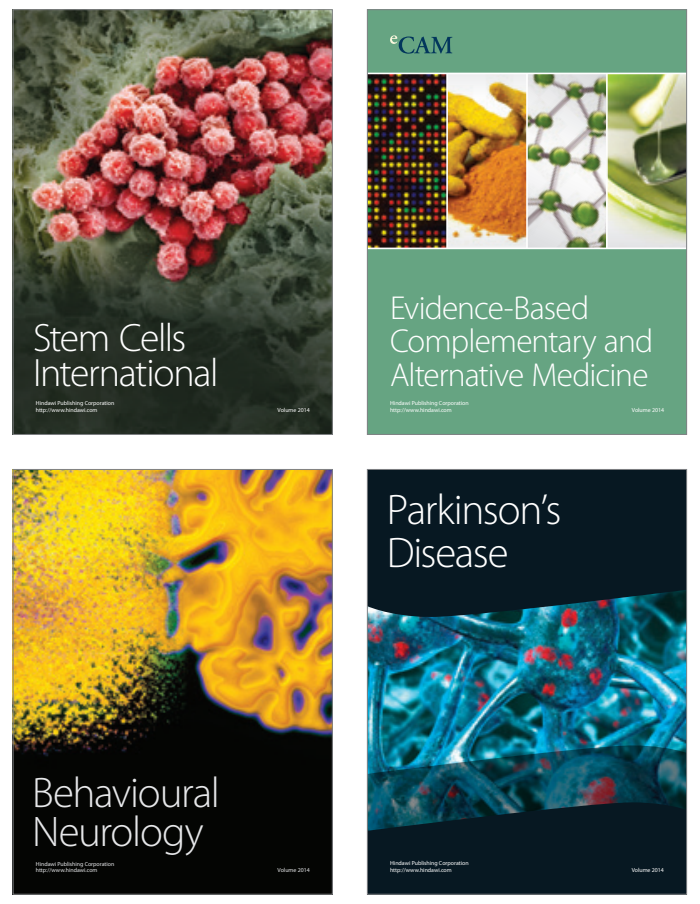
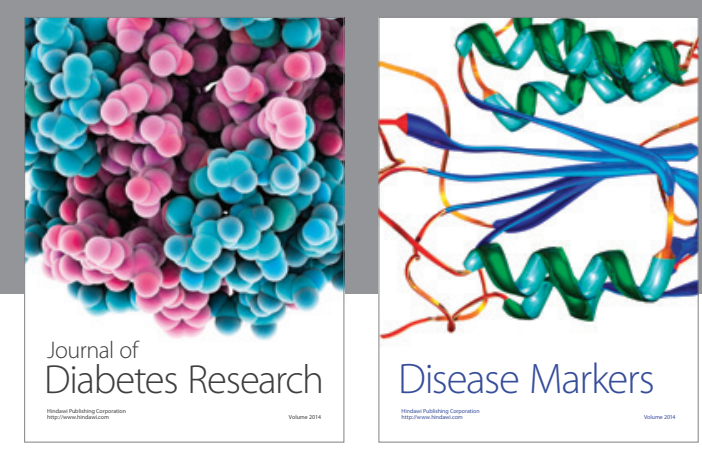

Disease Markers
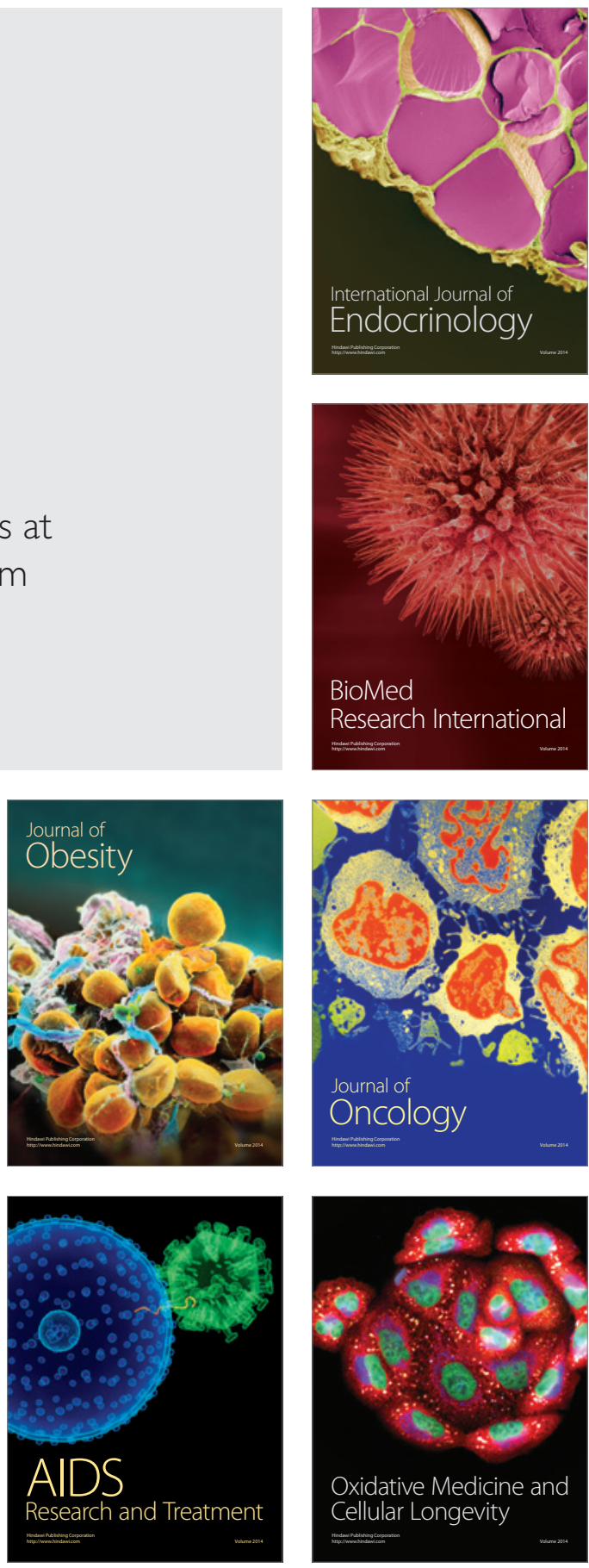